\title{
INFLUENCE OF DOPED-CHARGE TRANSPORT LAYERS ON THE PHOTOVOLTAIC PERFORMANCE OF DONOR-ACCEPTOR BLEND p-i-n TYPE ORGANIC SOLAR CELLS
}

\author{
D. Gebeyehu*, B. Maennig, J. Drechsel, K. Leo, and M. Pfeiffer \\ Institut für Angewandte Photophysik, Technische Universität Dresden, \\ George-Baehr Str. 1, D-01062 Dresden, Germany
}

(Received September 22, 2003; revised February 4, 2004)

\begin{abstract}
This report demonstrates external power conversion efficiencies of $2 \%$ under 100 $\mathrm{mW} / \mathrm{cm}^{2}$ simulated AM1.5 illumination for organic thin-film photovoltaic cells using a phthalocyanine-fullerene $\left(\mathrm{ZnPc} / \mathrm{C}_{60}\right)$ bulk heterojunction as an active layer, embedded into a p-i-n type architecture with doped wide-gap charge transport layers. For an optically optimized device, we found internal quantum efficiency (IQE) of above $80 \%$ under short circuit conditions. Such optically thin cells with high internal quantum efficiency are an important step towards high efficiency tandem cells. The p-i-n architecture allows for the design of solar cells with high internal quantum efficiency where only the photoactive region absorbs visible light and recombination losses at contacts are avoided. The I-V characteristics, power conversion efficiencies, the dependence of short circuit current on incident white light intensity, incident photon to collected electron efficiency (IPCE) and absorption spectra of the active layer system are discussed.
\end{abstract}

KEY WORDS: Doped-charge transport layers, Organic solar cells, Photovoltaic cells, Phthalocyanine-fullerene

\section{INTRODUCTION}

Organic materials are attractive alternatives to conventional semiconductors due to the relatively high cost for the input material. The processing of crystalline silicon wafers is high-level semiconductor technology, and as such expensive and very capital intensive. Today silicon solar cells dominate the photovoltaic market by $90 \%$ and the record efficiency for a laboratory cell is $25 \%$. On the other hand, organic photovoltaic devices offer great technological potential as a renewable and alternative source of electrical energy in contrast to conventional silicon photovoltaic devices. Therefore, the demand for inexpensive renewable energy sources is the driving force behind new approaches in the development of low-cost photovoltaic devices. However, the efficiencies of organic solar cells based on an interpenetrating network of a conjugated polymer or phthalocyanine and fullerene as donor and acceptor materials still need to be improved for commercial application.

In recent years, the power conversion efficiencies of thin-film organic photovoltaic cells have increased steadily and rapidly [1-17]. These significant improvements resulted from progress in material synthesis and purification methods and the introduction of novel device concepts such as small molecule-based bilayers [1-3] and blends [3-5], polymer/polymer bilayers [6, 7] and blends [8, 9], polymer/small molecule bilayers [10], polymer/fullerene bilayers [11] and blended devices [12-16], and exciton-blocking layers (EBL) [17]. The considerable activity has been spurred by their lightweight, potential low-cost, tuneability of the electronic band gap by chemical synthesis, less toxic manufacturing techniques, and the simple fabrication of large-area flexible, thin film devices. Because of these advantages, the development of organic solar cells will have a major impact.

*Corresponding author. E-mail: dgebeyehu@yahoo.com or gebeyehu@iapp.de 
Generally, the operation of an organic photovoltaic device comprises three consecutive fundamental steps: (1) absorption of light and creation of excitons, (2) creation of separate charges at the donor-acceptor interface, and (3) selective transport of the charges through the bulk of the device to the appropriate collecting electrodes. For the generation of electrical power by absorption of photons it is necessary to separate the electron-hole (e-h) pair generated by photoexcitation before recombination processes can takes place. In conjugated polymers as well as in phthalocyanine, the stabilization of the photoexcited e-h pair can be achieved by blending these materials with acceptor molecule, which has an electron affinity that is larger than the electron affinity of the polymer or phthalocyanine, but still smaller than its ionization potential. In addition, the highest occupied molecular orbital (HOMO) of the acceptor should be lower than the HOMO of the conjugated polymer or phthalocyanine. Under these conditions it is energetically favorable for the photoexcited donor molecule to transfer an electron to the acceptor molecule. Furthermore, in the case of donor-acceptor devices, an acceptor material with high electron mobility and a donor material with high hole mobility are ideal.

Phthalocyanine possesses good electron donating properties due to its large easily ionized $\pi$ electron system, whereas fullerene is a good $\pi$-electron acceptor, which can be connected with other organic molecules. Phthalocyanine-fullerene based molecular system is therefore a potential material candidate for a photovoltaic cell due to its large and flexible absorption combined with electrical properties similar to an organic semiconductor. Therefore, we have recently investigated the concept of p-i-n type bulk-heterojunction cells [5]. In the present work, we demonstrate that the efficiency of the p-i-n-bulk heterojunction photovoltaic cells can be significantly improved by employing materials for the transport layers with high mobilities and large band gap. In the active layer of the device, holes are transported through the zincphthalocyanine, and electrons are transported by hopping between fullerene molecules.

\section{EXPERIMENTAL}

The schematic energy level diagrams of the p-i-n-bulk heterojunction photovoltaic devices together with the chemical structures of the materials used and details of the thin-film production technique have been reported earlier [5]. For the p-doped hole transport layer (HTL), we replaced the previously 4,4',4"-tris(3-methylphenylphenylamino)-triphenylamine (mMTDATA) [5] with the N,N,N',N'-tetrakis(4-methoxyphenyl)-benzidine (MeO-TPD). The electron donating methoxy-substituents reduce the ionization energy of TPD such that the charge transfer from the matrix to the dopant 2,3,5,6-tetrafluoro-7,7,8,8-tetracyanochinodimethane $\left(\mathrm{F}_{4}\right.$-TCNQ) becomes complete like in m-MTDATA, while for $\mathrm{F}_{4}$-TCNQ in standard TPD only a partial charge transfer and low conductivities are found. Due to the higher hole mobility in TPD-derivatives as compared to TDATA derivatives [18], the resulting conductivity for a layer with $2 \% \mathrm{~F}_{4}$-TCNQ is about one order higher in MeO-TPD $\left(5 \times 10^{-6} \mathrm{~S} / \mathrm{cm}\right)$ than in m-MTDATA $\left(3 \times 10^{-7} \mathrm{~S} / \mathrm{cm}\right)$. The $n$-doping of the electron transport materials perylene3,4,9,10-tetracaroxylic-N,N'-dimethyl-diimide (short name methyl-perylene-pigment: MPP) and $\mathrm{C}_{60}$ is by coevaporation with $2 \%$ rhodamine $\mathrm{B}$, which leads to conductivities on the order of $10^{-4}$ $\mathrm{S} / \mathrm{cm}$. As shown previously by Werner et al. [19], rhodamine B being a salt of a cationic dye turns into a strong donor upon evaporation.

The devices have been fabricated on semi-transparent ITO coated glass substrates (TFD Thin film Devices Inc.) with a surface resistance of $<50 \mathrm{Ohm} /$ square. The typical active area of our devices is $2-3 \mathrm{~mm}^{2}$. The organic materials were obtained commercially and purified using thermal gradient sublimation. Light intensities have been measured by a calibrated silicon photodiode for an AM1.5 spectrum. The current-voltage (I-V) characteristics have been measured with a Keithley SMU 236 source measurement unit in situ under vacuum with 1/10

Bull. Chem. Soc. Ethiop. 2004, 18(1) 
sun and in nitrogen atmosphere under 1 sun, standard AM1.5 illumination provided by a metal halogen lamp (SOL 1200 Solar Simulator). The data have not been corrected for a possible spectral mismatch between the solar simulator and the ideal AM1.5 spectrum. According to [13, 14], the measurement of the spectral sensitivity of the reference cell and the test cell and measurement of the spectrum of the solar simulator together with the defined spectrum AM1.5 enables the determination of the solar simulator spectral mismatch factor. Using the shape of the absorption spectrum as an approximation for the IPCE spectrum and the emission spectrum of the solar simulator delivered by the provider, we estimate that the real AM1.5 efficiency should be $15 \%$ higher than the values given here.

The dependence of the short circuit current on white light intensity has been taken using various neutral density metal filters in nitrogen atmosphere. For the reflection measurement, near normal incident $\left(5^{\circ}\right)$ reflection spectra of the vacuum deposited thin-films on ITO-coated glass substrates were recorded with a SHIMADZU spectrometer (UV-3100). Optical absorption spectra of single layers on glass were measured with the same device.

\section{RESULTS AND DISCUSSION}

The calculation of the overall energy conversion efficiency, $\eta_{\mathrm{e}}$ has been performed using the equation

$$
\eta_{\mathrm{e}}=\left(\mathrm{V}_{\mathrm{oc}} * \mathrm{I}_{\mathrm{sc}} * \mathrm{FF}\right) / \mathrm{P}_{\mathrm{inc}},
$$

where $V_{\text {oc }}, I_{s c}, F F$ and $P_{\text {inc }}$ are the open circuit voltage, the short circuit current density, the fill factor and the incident light power on the device as measured by a calibrated reference cell, respectively. We determine the value of the fill factor of the device, $\mathrm{FF}$, from the point $\left(\mathrm{V}_{\max }\right.$, $\left.\mathrm{I}_{\max }\right)$ in the $4^{\text {th }}$ quadrant of the I-V characteristics with the maximum electrical power according to

$$
\mathrm{FF}=\left(\mathrm{V}_{\max } * \mathrm{I}_{\max }\right) /\left(\mathrm{V}_{\mathrm{oc}} * \mathrm{I}_{\mathrm{sc}}\right)
$$

Figure 1 shows the device structure and performance of a series of samples with a photoactive layer of $\mathrm{ZnPc}_{6} \mathrm{C}_{60}(50 \mathrm{~nm}$, molar blend ratio 1:2) embedded between different p-doped hole transport layers (HTLs) and n-doped electron transport layers (ETLs). For sample A, m-MTDATA and MPP are used as matrix materials for the HTL and the ETL, respectively. As reported previously [5], such devices show good performance under low illumination. However, the performance under a full sun illumination (fill factor and short circuit photocurrent) is seriously affected by the series resistance, determined by the low conductivity of doped m-MTDATA. This problem has now been overcome by replacing m-MTDATA with MeO-TPD as a matrix material for the p-doped HTL (device B). As compared to device A, the slope of the I-V characteristics, both in the dark and under illumination, for forward bias above $0.5 \mathrm{~V}$ is significantly increased leading to a higher fill factor, FF (0.5 instead of 0.33$)$ and a higher short circuit photocurrent, $I_{\mathrm{sc}}\left(7 \mathrm{~mA} / \mathrm{cm}^{2}\right.$ instead of $\left.6.3 \mathrm{~mA} / \mathrm{cm}^{2}\right)$ under $\mathrm{AM} 1.5$ illumination (Figure 1(c)).

A drawback of devices using MPP or 3,4,9,10-perlenetetracarboxylic-bis-benzimidazole (PTCBI) as matrix material for the ETL is that the $50 \mathrm{~nm}$ thick layer of this dark red material absorbs a significant amount of light, while - according to the low exciton diffusion length only a few nanometers close to the photoactive blend layer actually contribute to the photocurrent. Therefore, we replaced the single ETL of $50 \mathrm{~nm}$-doped MPP (devices A and B) by an undoped interlayer of $10 \mathrm{~nm}$ PTCBI followed by $50 \mathrm{~nm}$-doped $\mathrm{C}_{60}$ (device C). As the 
first absorption peak of $\mathrm{C}_{60}$ is at about $2.8 \mathrm{eV}$, it is basically transparent in the range of the first absorption peak of PTCBI at $2.2 \mathrm{eV}$. Therefore, it is obvious that device $\mathrm{C}$ should have much higher internal quantum efficiency in this spectral range than device B. However, as shown in Figure 1(c), it exhibits also a significantly enhanced $\mathrm{I}_{\mathrm{sc}}$. This is to be expected because device $\mathrm{C}$, having a wide gap ETL, uses the light that is reflected at the Al top contact more efficiently than device $\mathrm{B}$. Additionally, it might play a role that excitons in PTCBI that travel to the $\mathrm{C}_{60}$ interface are reflected there and have another chance to reach the interface of the mixed layer where they are separated into an electron on PTCBI and a hole on ZnPc. The lack of saturation of the I-V characteristics at $-1 \mathrm{~V}$ under illumination for device $\mathrm{C}$ is not a shunt resistance as it is obvious from the dark characteristics. It rather indicates field dependent recombination losses or field dependent carrier generation efficiency in the PTCBI layer.
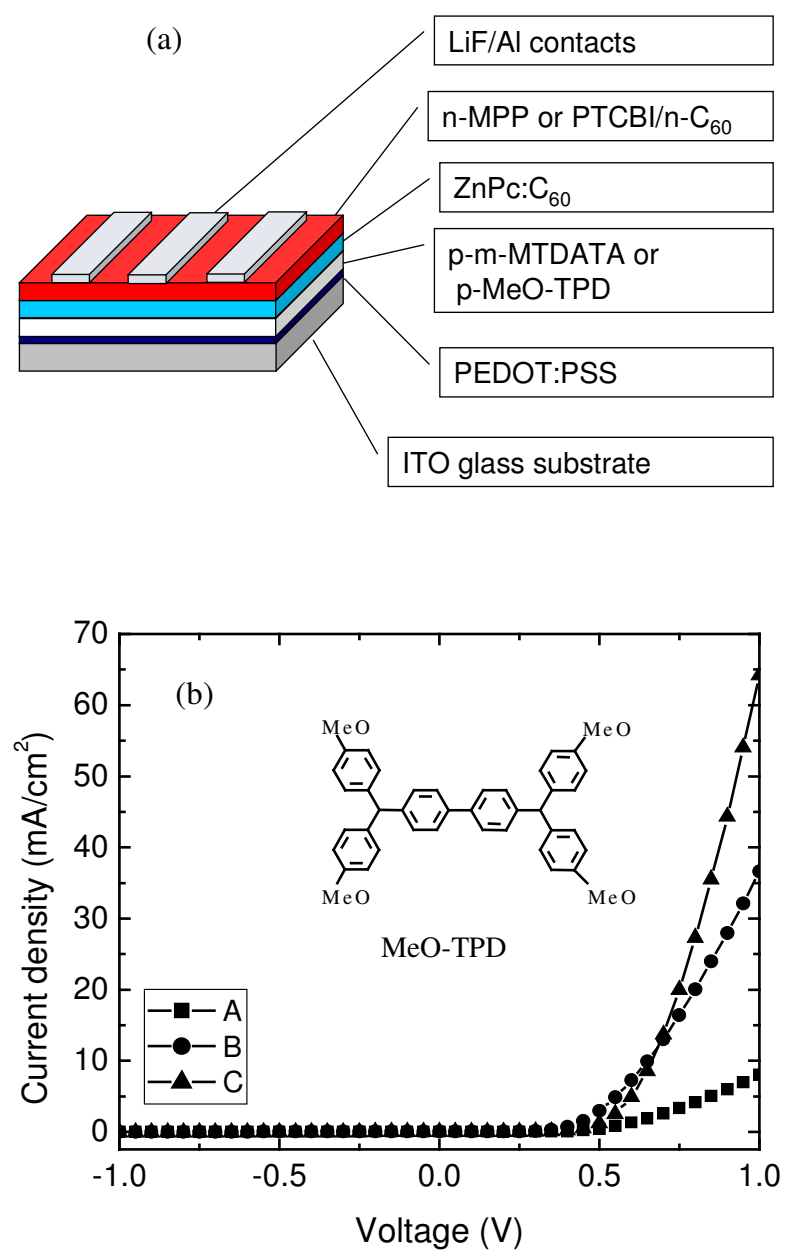

Bull. Chem. Soc. Ethiop. 2004, 18(1) 


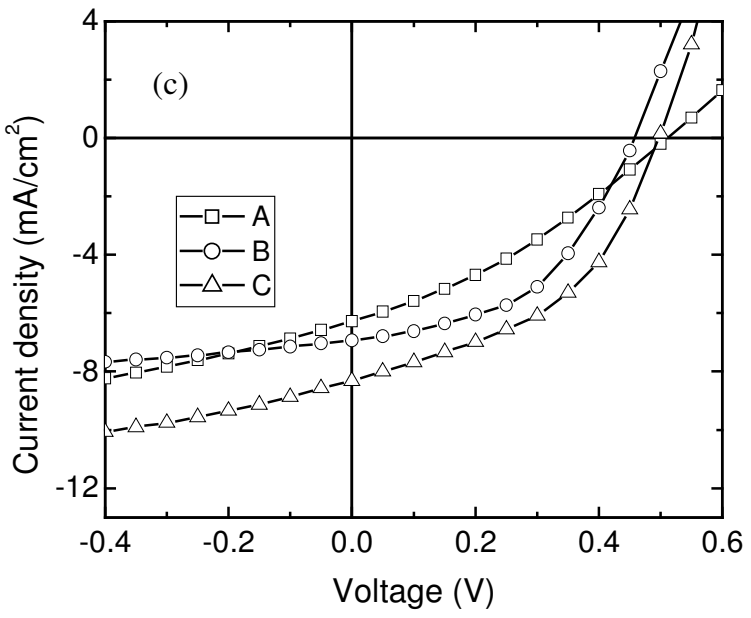

Figure 1. Device structure and characterization. (a) p-i-n type bulk-heterojunction organic solar cells, (b) and (c) influence of charge transport layers on the I-V characteristics of $\mathrm{p}-\mathrm{i}-\mathrm{n}$ bulk heterojunction devices with the layer sequence ITO/PEDOT:PSS (40 nm)/HTL/50 $\mathrm{nm}$ ZnPc: $\mathrm{C}_{60}(1: 2) / E T L / \mathrm{LiF}(1 \mathrm{~nm}) / \mathrm{Al}(70 \mathrm{~nm})$. Device $\mathrm{A}: \mathrm{HTL}=\mathrm{p}$-doped $\mathrm{m}$ MTDATA $(50 \mathrm{~nm})$; ETL $=$ n-doped MPP $(50 \mathrm{~nm})$. Device B: HTL $=$ p-doped MeOTPD $(50 \mathrm{~nm}) ; \mathrm{ETL}=\mathrm{n}$-doped MPP $(50 \mathrm{~nm})$. Device C: HTL = p-doped MeO-TPD (50 $\mathrm{nm}) ; \mathrm{ETL}=$ undoped PTCBI $(10 \mathrm{~nm}) / \mathrm{n}$-doped $\mathrm{C}_{60}(50 \mathrm{~nm})$. For all samples, p-doping is by admixture of $2 \mathrm{~mol} \% \mathrm{~F}_{4}$-TCNQ and n-doping by $2 \mathrm{~mol} \%$ rhodamine $\mathrm{B}$. Figure $1(\mathrm{~b})$ in dark and Figure 1(c) under 1 sun, AM1.5 $\left(100 \mathrm{~mW} / \mathrm{cm}^{2}\right)$ illumination. The inset in Figure 1(b) shows the chemical structure of MeO-TPD.

Altogether, the characteristic parameters of device $\mathrm{C}$ are $\mathrm{I}_{\mathrm{sc}}$ of $8.3 \mathrm{~mA} / \mathrm{cm}^{2}$, open circuit voltage, $\mathrm{V}_{\mathrm{oc}}$ of $500 \mathrm{mV}$, FF of 0.5 , and energy conversion efficiency of $2 \%$ under AM1.5 (100 $\mathrm{mW} / \mathrm{cm}^{2}$ ) illumination. However, the slope of the characteristics under illumination around $\mathrm{V}=$ $\mathrm{V}_{\mathrm{oc}}$ and thus the fill factor are still limited by the series resistance. Accordingly, it was found that the fill factor and the power efficiency are higher at lower illumination levels for all devices (e.g. $\mathrm{FF}=0.6$ for device $\mathrm{B}$ at $10 \mathrm{~mW} / \mathrm{cm}^{2}$ white light illumination). The benefit of embedding the intrinsic active layer system between doped organic wide gap materials is that one can design cells where only the photoactive layer absorbs light. Recombination losses at contacts or damage of the active layer by metal deposition are avoided and the cells make optimum use of the light reflected at the back contact electrode.

To investigate the short circuit current behaviour at higher light intensities, we have studied the dependence of the short circuit current on the incident white light intensity. As shown in Figure 2, the short circuit photocurrents, $\mathrm{I}_{\mathrm{sc}}$ of devices B and $\mathrm{C}$ scale exactly linearly with the light intensity $\mathrm{I}_{\mathrm{inc}}$ up to more than $100 \mathrm{~mW} / \mathrm{cm}^{2}$, i.e. $\mathrm{I}_{\mathrm{sc}} \sim \mathrm{I}_{\text {inc }}{ }^{\alpha}$ with the scaling exponent $\alpha=1$. This proves that no non-linear effects like direct recombination of electrons and holes in the mixed layer or quenching of excitons by free carriers play a significant role. Furthermore, it confirms that $I_{s c}$ is not affected by the series resistance for these devices. Otherwise, the influence of a series resistance or bimolecular recombination would lead to a sub-linear behaviour and finally to a saturation of photocurrent at higher light intensities [12]. 


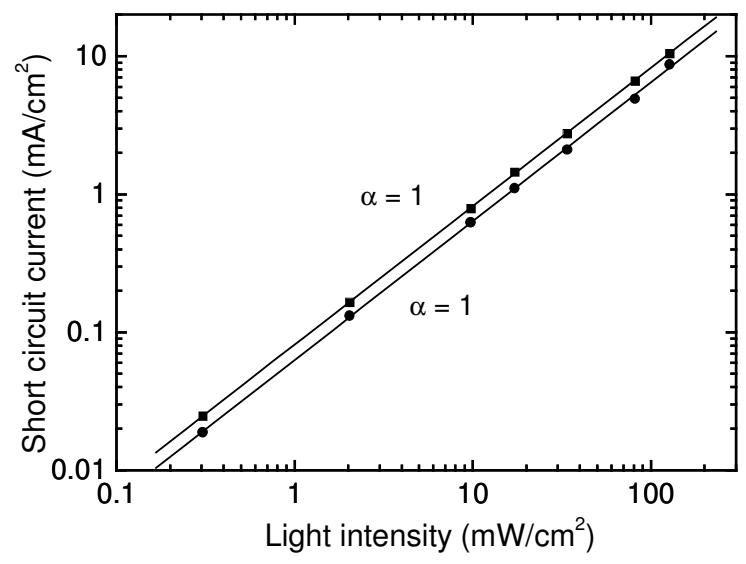

Figure 2. Dependence of the short circuit current versus incident light intensity of an ITO/PEDOT:PSS (40 nm)/p-MeO-TPD (50 nm)/50 nm ZnPc: $\mathrm{C}_{60}(1: 2) / \mathrm{PTCBI}(10$ $\mathrm{nm}) / \mathrm{n}-\mathrm{C}_{60}(50 \mathrm{~nm}) / \mathrm{LiF}(1 \mathrm{~nm}) / \mathrm{Al}(70 \mathrm{~nm})$ (solid squares) and ITO/PEDOT:PSS (40 $\mathrm{nm}) / \mathrm{p}-\mathrm{MeO}-\mathrm{TPD}(50 \mathrm{~nm}) / 50 \mathrm{~nm} \mathrm{ZnPc:C_{60 }}(1: 2) / \mathrm{n}-\mathrm{MPP}(50 \mathrm{~nm}) / \mathrm{LiF}(1 \mathrm{~nm}) / \mathrm{Al}$ (70 $\mathrm{nm}$ ) (solid circles) p-i-n bulk heterojunction devices. Lines are fits to a power law and are discussed in the text.

In order to exploit the potential of such devices both the optical absorption spectra of the active layer system and the IPCE (i.e. incident photon to collected electron efficiency) are investigated. The optical absorption spectra of the active layer system of device $\mathrm{C}$ in Figure 1, comprising a $\mathrm{ZnPc}: \mathrm{C}_{60}$ blend layer $(1: 2,50 \mathrm{~nm})$ and a pure PTCBI layer $(10 \mathrm{~nm})$, derived from reflection measurements. As it can be seen in Figure 3(a), the maximum value of $36 \%$ absorption of the active layer system was reached at $684 \mathrm{~nm}$, which mainly stems from ZnPc. Polycrystalline $\mathrm{ZnPc}$ in the $\alpha$-phase has a strong absorption band between 1.5 and $2.2 \mathrm{eV}$, with peaks at 704 and $616 \mathrm{~nm}$ [21]. However, the splitting between these two peaks is somewhat lower for $\mathrm{ZnPc}$ in a blend with $\mathrm{C}_{60}$ which is a hint for a predominantly amorphous morphology. The peak value of $30 \%$ absorption at $488 \mathrm{~nm}$ corresponds to an absorption peak of PTCBI at $532 \mathrm{~nm}$ with an additional contribution from $\mathrm{C}_{60}$. Accordingly, the incorporation of PTCBI interlayer in combination with an ETL of $\mathrm{C}_{60}$ having a wider band gap improves significantly the device performance (as shown in Figure 1(c)), which can be attributed to an increased harvesting of light in the spectral range of the PTCBI absorption with its peak at $532 \mathrm{~nm}$ and a long tail up to $800 \mathrm{~nm}$. On the other hand, the first strong absorption peak of pure $\mathrm{C}_{60}$ films is at $450 \mathrm{~nm}$ with only a weak tail of more or less forbidden transitions extending to longer wavelengths [22]. Accordingly, $\mathrm{C}_{60}$ is basically transparent in the main absorption regions of $\mathrm{ZnPc}$ and PTCBI.

On the other hand, in Figure 3(b) the result of the IPCE or the external quantum efficiency measurement for the same device $\mathrm{C}$ in Figure 1 is shown. Unfortunately, this measurement was done from degraded and unprotected sample, which was exposed to air for several weeks. Even though, a maximum external quantum efficiency or IPCE of $31 \%$ at a wavelength of $695 \mathrm{~nm}$ was observed, which comes mainly from ZnPc. In addition, a maximum in IPCE of $29 \%$ was reached at a wavelength of $405 \mathrm{~nm}$, which results mainly from $\mathrm{C}_{60}$. Surprisingly, in a photoactive layer of $\mathrm{ZnPc}_{6} \mathrm{C}_{60}\left(50 \mathrm{~nm}\right.$, molar blend ratio 1:2) system, $\mathrm{C}_{60}$ contributed significantly to the photocurrent as efficient as $\mathrm{ZnPc}$. The photocurrent contribution of $\mathrm{C}_{60}$ is

Bull. Chem. Soc. Ethiop. 2004, 18(1) 
generated from between $\lambda=400 \mathrm{~nm}$ and $550 \mathrm{~nm}$, while the ZnPc contributes from $\lambda=550 \mathrm{~nm}$ to $800 \mathrm{~nm}$, such that the solar spectrum at $\lambda<750 \mathrm{~nm}$ is completely covered. The IPCE follows the absorption closely in the range where the $\mathrm{ZnPc}, \mathrm{C}_{60}$ and PTCBI absorb. Interestingly, these materials are well suited for p-i-n type bulk-heterojunction solar cells as they provide good coverage of the solar spectrum. Based on the above evidences, external quantum efficiency (IPCE) above $50 \%$ could be estimated from an efficient photovoltaic device of such a system.
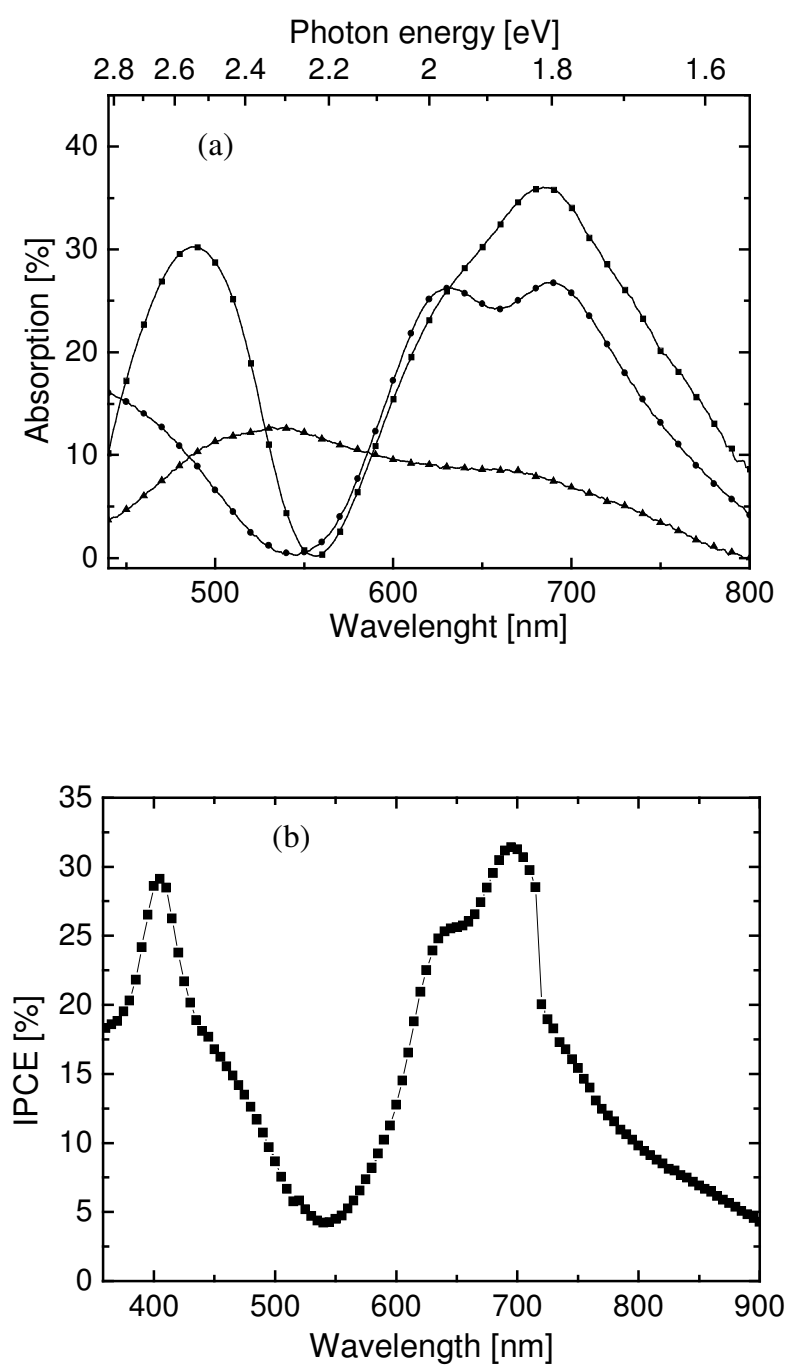

Bull. Chem. Soc. Ethiop. 2004, 18(1) 
Figure 3. (a) Optical absorption spectra of the active layer of device $\mathrm{C}$ in Figure 1 as a function of wavelength \{solid squares\}, determined from the difference in reflection spectra between two comparative samples with and without the photoactive layers. The two samples have the same total thickness and the layer sequences ITO/MeO-TPD(50 $\mathrm{nm}) / \mathrm{ZnPc}: \mathrm{C}_{60}(1: 2,50 \mathrm{~nm}) / \mathrm{PTCBI}(10 \mathrm{~nm}) / \mathrm{C}_{60}(50 \mathrm{~nm}) / \mathrm{Al}(100 \mathrm{~nm})$ and ITO/MeO$\left.\mathrm{TPD}(110 \mathrm{~nm}) / \mathrm{C}_{60}(50 \mathrm{~nm}) / \mathrm{Al}(100 \mathrm{~nm})\right)$, respectively. For comparison, simple absorption spectra of a $\mathrm{ZnPc}: \mathrm{C}_{60}$ blend layer $(1: 2,50 \mathrm{~nm})$ \{solid circles $\}$ and of PTCBI $(10 \mathrm{~nm})$ \{solid up triangles $\}$ on quartz glass are shown. (b) External quantum efficiency (IPCE) of $\mathrm{ZnPc}: \mathrm{C}_{60}(50 \mathrm{~nm}$, molar blend ratio 1:2) degraded device (i.e. the same device $\mathrm{C}$ in Figure 1) as a function of wavelength. Unfortunately, this device was exposed to air for several weeks before the IPCE measurement was done. The charge transport layers, which were used for this device structure, are: $\mathrm{HTL}=\mathrm{p}$-doped MeOTPD $(50 \mathrm{~nm})$; ETL $=$ undoped PTCBI $(10 \mathrm{~nm}) / \mathrm{n}$-doped $\mathrm{C}_{60}(50 \mathrm{~nm})$. For all samples, p-doping is by admixture of $2 \mathrm{~mol} \% \mathrm{~F}_{4}$-TCNQ and n-doping by $2 \mathrm{~mol} \%$ rhodamine $\mathrm{B}$.

\section{CONCLUSION}

In conclusion, efficient organic photovoltaic devices have been fabricated based on a $p-i-n$ type bulk-heterojunction device architecture using doped wide-gap charge transport layers. For a device with a photoactive layer system consisting of a $\mathrm{ZnPc}: \mathrm{C}_{60}$ blend and a neat PTCBI layer, an overall energy conversion efficiency of about $2 \%$ under 1 sun, standard AM1.5 (100 $\mathrm{mW} / \mathrm{cm}^{2}$ ) illumination were determined. This is almost two times higher than all previously reported values for solar cells based on phthalocyanine: $\mathrm{C}_{60}$ blends [4] or phthalocyanine/perylene-dye double layer cells $[1,2,20]$, which proves the general significance of the p-i-n concept. However, the efficiency values in this study are underestimated, since the calculated spectral mismatch factor is significantly higher than unity. That means, the real power conversion efficiency should be $15 \%$ higher (i.e. 2.3\%). The high internal quantum efficiency over a broad spectral range opens a way to highly efficient organic solar cells using light trapping schemes or tandem architectures.

\section{ACKNOWLEDGEMENTS}

The first author acknowledge all the members of the organic optoelectronic group, Institut für Angewandte Photophysik, Technische Universität Dresden for the friendly and stimulating working atmosphere. We acknowledge J. Riedel, and V. Dyakonov (Energy and Semiconductor Laboratory, Institute of Physics, University of Oldenburg, Germany) for giving us the chance to measure the IPCE or the external quantum efficiency characteristic of our device. Furthermore, the authors acknowledge the support of the German Secretary for Education and Science (BMBF, contract number 01SF0027 and 01SF0119).

\section{REFERENCES}

1. Tang, C.W. Appl. Phys. Lett. 1986, 48, 183.

2. Wöhrle, D.; Meissner, D. Adv. Mater. 1991, 3, 129.

3. Petrisch, K.; Dittmer, J.J.; Marseglia, E.A.; Friend, R.H.; Lux, A.; Rozenberg, G.G.; Moratti, S.C.; Holmes, A.B. Sol. Energy Mater. Sol. Cells 2000, $61,63$.

4. Rostalski, J.; Meissner, D. Sol. Energy Mater. Sol. Cells 2000, 61, 87. 
5. Gebeyehu, D.; Maennig, B.; Drechsel, J.; Leo, K.; Pfeiffer, M. Sol. Energy Mater. Sol. Cells 2003, 79, 81.

6. Tada, K.; Onoda, M.; Nakayama, H.; Yoshino, K. Synth. Met. 1999, 102, 982.

7. Jenekhe, S.A.; Yi, S. Appl. Phys. Lett. 2000, 77, 2635.

8. Yu, G.; Heeger, A. J. Appl. Phys. Lett. 1995, 78, 4510.

9. Granström, M.; Petritsch, K.; Arias, A.C.; Lux, A.; Andersson, M.R.; Friend, R.H.J. Nature 1998, 395, 257.

10. Halls, J.J.M.; Friend, R.H. Synth. Met. 1997, 85, 1307.

11. Sariciftci, N.S.; Braun, D.; Zhang, C.; Srdanov, V.I.; Heeger, A.J.; Stucky, G.; Wudl, F. Appl. Phys. Lett. 1993, 62, 585.

12. Gebeyehu, D.; Brabec, C.J.; Padinger, F.; Fromherz, T.; Hummelen, J.C.; Badt, D.; Schindler, H.; Sariciftci, N.S. Synth. Met. 2001, 118, 1.

13. Shaheen, S.E.; Brabec, C.J.; Padinger, F.; Fromherz, T.; Hummelen, J.C.; Sariciftci, N.S. Appl. Phys. Lett. 2001, 78, 841.

14. Kroon, J.M.; Wienk, M.M.; Verhees, W.J.H.; Hummelen, J.C. Thin Solid Films 2002, 403404, 223

15. Wienk, M.M.; Kroon, J.M.; Verhees, W.J.H.; Knol, J.; Hummelen, J.C.; van Hal, P.A.; Janssen, R.A.J. Angew. Chem. Int. Ed. 2003, 42, 3371.

16. Schilinsky, P.; Wadauf, C.; Brabec, J.C., Appl. Phys. Lett. 2002, 81, 3885; Padinger, F.; Rittberger, R.S.; Sariciftci, N.S. Adv. Funct. Mater. 2003, 13, 1.

17. Peumans, P.; Forrest, S.R. Appl. Phys. Lett. 2001, 79, 126.

18. Shirota, Y. J. Mater. Chem. 2000, 10, 1.

19. Werner, A.G.; Li, F.; Harada, K.; Pfeiffer, M.; Fritz, T.; Leo, K. Appl. Phys. Lett. 2003, 82, 4495.

20. Peumans, P.; Bulovic, V.; Forrest, S.R. Appl. Phys. Lett. 2000, 76, 2650.

21. Lane, P.A.; Rostalski, J.; Giebeler, C.; Martin, S.J.; Bradley, D.D.C.; Meissner, D. Sol. Energy Mater. Sol. Cells 2000, 63, 3.

22. Chen, L.; Godovsky, D.; Inganaes, O.; Hummelen, J.C.; Janssens, R.A.J.; Svensson, M.; Andersson, M.R. Adv. Mater. 2000, 12, 1367. 